\title{
Revisão da produção científica sobre análise de conjuntura: contribuição à análise política em saúde
}

\author{
Review of scientific production on conjuncture analysis: contribution \\ to political analysis in health
}

João Henrique Araujo Virgens' ${ }^{\mathbf{1}}$, Carmen Fontes Teixeira $\mathbf{2}$

DOI: 10.1590/0103-11042018S226

RESUMO Diversas abordagens desenvolvidas no âmbito das ciências humanas e sociais têm sido utilizadas nas análises políticas em saúde, uma delas é a análise de conjuntura. Com objetivo de sistematizar os principais conceitos, referenciais e estratégias metodológicas desse tipo de estudo e problematizar sua aplicação na área da saúde, foi realizada uma revisão sistemática sobre o tema. Não foi identificada uma única vertente teórica de referência nem um percurso metodológico padrão, mas merece destaque o fato de a maioria dos artigos não se preocupar em explicitar, de maneira clara, teorias e métodos. Os artigos que deram enfoque à dimensão política incluíram, entre seus objetivos, analisar fatos e atores envolvidos. Sobre os artigos que tratam de questões de saúde, foi possível notar maior preocupação com aspectos teóricos e metodológicos, sendo que todos comentaram sobre a relação entre o setorial e outras dimensões de caráter político e/ou estrutural. Ao considerar que a análise de conjuntura tem o propósito de subsidiar a ação, constata-se que, quando limitada a um setor, restringe a visão acerca das determinações que incidem sobre os fatos e atores, inclusive em saúde, condição que pode prejudicar a tomada de decisão.

PAlAVRAS-CHAVE Política. Política de saúde. Análise de situação. Análise de conjuntura. Análise política em saúde.

ABSTRACT Several approaches developed in the humanities and social sciences have been used in the political analysis in health, one of them is the conjuncture analysis. In order to systematize the main concepts, references and methodological strategies of this type of study and to prob-

1 Universidade Federal da Bahia (UFBA), Instituto de Saúde Coletiva (ISC) Salvador (BA), Brasil. Orcid: https://orcid. org/0000-0001-9119$280 \mathrm{X}$

jhenrique.av@gmail.com

2 Universidade Federal da Bahia (UFBA), Instituto de Humanidades, Artes e Ciências Professor Milton Santos (IHAC) - Salvador (BA), Brasil.

Orcid: https://orcid. org/0000-0002-80809146

carment@ufba.br lematize its application in the health area, a systematic review was carried out on the subject. It was not identified a single theoretical reference or a standard methodology, but it is worth highlighting the fact that most articles do not bother to clearly explain theories and methods. The articles that focused on the political dimension included, among their objectives, analyzing facts and social actors involved. Regarding the articles that deal with health issues, it was possible to note a greater concern with theoretical and methodological aspects, and all commented about the relationship between the sectorial and other dimensions of a political and structural nature. Considering that the conjuncture analysis has the purpose of subsidizing the action, it is observed that when it is limited to a sector, it restricts the vision related to determinations that affect the facts and social actors, including in health, a condition that may harm the decision making.

KEYWORDS Politics. Health policy. Analysis of situation. Conjunctural analysis. Political analysis in health. 


\section{Introdução}

Este artigo é parte de uma pesquisa sobre abordagens teórico-metodológicas utilizadas nas 'análises políticas em saúde’1, vertente de estudos assimilada pela área de 'política, planejamento e gestão em saúde'2${ }^{5}$, que incorpora variadas contribuições das ciências humanas e sociais, assumindo "o poder como categoria de análise central, [...] assim como as suas relações com a produção de fatos, dentro e fora das instituições"6(34). Nesse tipo de estudo, um dos grandes desafios envolve a realização de análises de conjuntura $^{6}$, que se debruçam sobre determinações, sobre processos políticos e, na dimensão setorial, sobre seus efeitos no sistema e na situação de saúde.

Apesar de não ser raro encontrar análises conjunturais na construção da teoria política, "não há facilmente nenhuma teorização mais sistemática sobre ela"7(2), e sua prática se daria de maneira, até certo ponto, 'intuitiva'7. Não haveria também uma formulação sistematizada que se compare a um livro como 'As regras do método sociológico', de Durkheim, e isso aponta a necessidade de aprofundar elementos teórico-metodológicos que alicercem a análise ${ }^{\mathbf{8}}$.

No caso da saúde, uma revisão preliminar não revelou estudos que aprofundem e problematizem a fundamentação teórico-metodológica da análise de conjuntura. Diante disso, realizou-se uma revisão sistemática da produção científica sobre essa abordagem, com objetivo de sistematizar os conceitos, referenciais e estratégias metodológicas utilizadas por autores nas diversas áreas, buscando-se, ademais, analisar como este tipo de estudo tem sido realizado na área de saúde.

A revisão fundamentou-se nas seguintes questões de pesquisa: quais as características da produção científica nacional sobre análise de conjuntura? Quais conceitos, teorias e métodos têm alicerçado a realização dessas análises? Existem diferenças teórico-metodológicas significativas nos estudos da área da saúde que realizam análise de conjuntura?

\section{Material e métodos}

Trata-se de uma revisão sistemática-12, estratégia caracterizada pelo rigor na concretização e descrição dos passos seguidos e pelo foco em uma questão específica, sendo necessário selecionar estudos que possam ser comparados para permitir a identificação de suas semelhanças e diferenças.

A busca foi realizada no dia 16 de maio de 2018 no Portal de periódicos da Capes (Coordenação de Aperfeiçoamento de Pessoal de Nível Superior), Scientific Electronic Library Online (SciELO) e Biblioteca Virtual em Saúde, utilizando-se os descritores 'análise de conjuntura', 'análise da conjuntura' e 'análise conjuntural'. Posteriormente, foi realizada uma busca complementar com as variações verbais da expressão 'analisar a conjuntura' (analis/o /a /amos /am /ada /ei /ou /aram /arei / aremos /arão), visando identificar estudos que assumem como objetivo realizar esse tipo de análise. Não foram estabelecidos critérios de temporalidade nem delimitadas as áreas de conhecimento, sendo o único critério de inclusão dos artigos o fato de terem sido 'revisados por pares'. Com base na leitura dos títulos e resumos, foram excluídos estudos repetidos (19) e outros por impertinência temática (98), ou seja, aqueles que apenas citavam os termos indicados sem efetivamente desenvolver esse tipo de abordagem. 


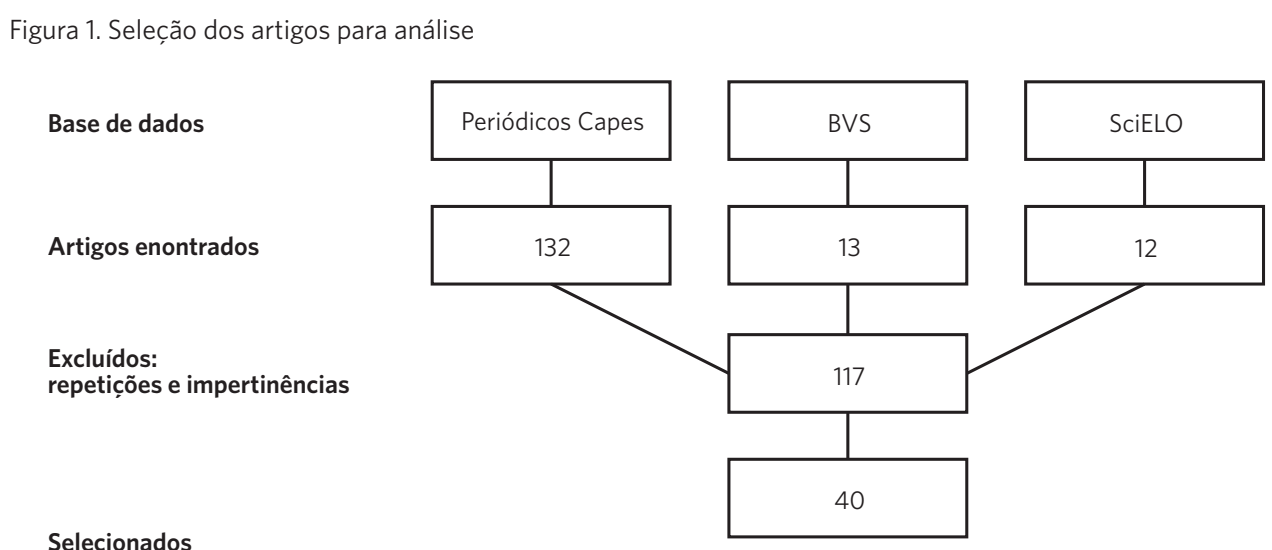

Fonte: Elaboração própria.

Os 40 artigos selecionados foram lidos na íntegra, de modo a extrair um conjunto de informações sistematizadas em uma matriz, contendo os seguintes elementos: ano de publicação; revista na qual foi publicado; perfil profissional dos autores (com base no CV registrado na Plataforma Lattes); objetivos; definição de 'conjuntura'; recorte temporal; recorte espacial/territorial; referenciais teóricos explicitados; métodos e técnicas de produção e análise de dados. Com base nessas informações, foi feita a análise das características gerais da produção científica selecionada com base na sua evolução temporal e na distribuição por áreas de conhecimento, bem como tratou-se de aprofundar a análise de conteúdo, com base nas categorias explicitadas.

\section{Resultados e discussão}

Um primeiro aspecto que chama a atenção na produção científica selecionada foi o fato de cinco artigos serem ensaios, que discutem aspectos teórico-metodológicos da análise de conjuntura. Apesar das suas contribuições para o tema, não apresentam elementos que se enquadram na maioria das categorias de análise propostas. Entretanto, cabe mencionar brevemente o conteúdo de cada um deles, na medida em que expressam o interesse de pesquisadores pela reflexão e problematização teórico-metodológica sobre análise de conjuntura. Desses, o artigo de Cruz ${ }^{8(145)}$ "versa sobre a lógica da análise de conjunturas políticas" e é desenvolvido com problematizações teórico-metodológicas que evidenciam tanto referenciais como sugestões de como o analista poderia construir seu método. Turolla et al. ${ }^{13}$, por sua vez, focam em aspectos metodológicos relacionados com o desenvolvimento de análises de conjuntura econômica, visando "reunir alguns elementos e reflexões sobre as atividades realizadas principalmente pelos macroeconomistas de mercado"13(18), também chamados pelos autores de "analistas de conjuntura"13(18). Mendonça Filho e Vasconcelos ${ }^{14}$ problematizam o 'confinamento' enquanto forma de controle, materializado nas políticas de segurança e saúde mental, citando categorias do referencial marxiano, mas sua discussão aprofunda o 'referencial foucaultiano' e a 'etno-pesquisa-interferência' baseada nas formulações da "sócio-análise francesa e da etnometodologia"14(134).

Outros dois artigos apenas estabelecem pontes com a análise de conjuntura. $\mathrm{O}$ artigo de Wiese ${ }^{15(34)}$ visa "evidenciar a relevância da discussão do social no âmbito da prática profissional na área da Saúde" e comenta sobre a importância dessa compreensão do 
social para esse tipo de análise. Barbosa e Ferreira ${ }^{16}$ problematizam o teatro do oprimido em diversas dimensões e evidenciam conexões teóricas e metodológicas entre essas abordagens, já que o teatro poderia ser utilizado como método para um processo coletivo de análise de conjuntura. Os demais ${ }^{17-}$ 51, que apresentam resultados de análises empíricas a partir de temáticas, estratégias metodológicas e referenciais variados, serão tratados com mais detalhes a seguir.

\section{Quais as principais características dos artigos selecionados?}

A distribuição temporal das 35 publicações analisadas evidencia uma tendência a aumento ao longo do tempo, especialmente na última década (gráfico 1), sem que, entretanto, identifique-se, na leitura dos artigos, algo em comum que justifique o aumento do interesse dos pesquisadores por este tema.

Gráfico 1. Distribuição temporal dos artigos de análise de conjuntura

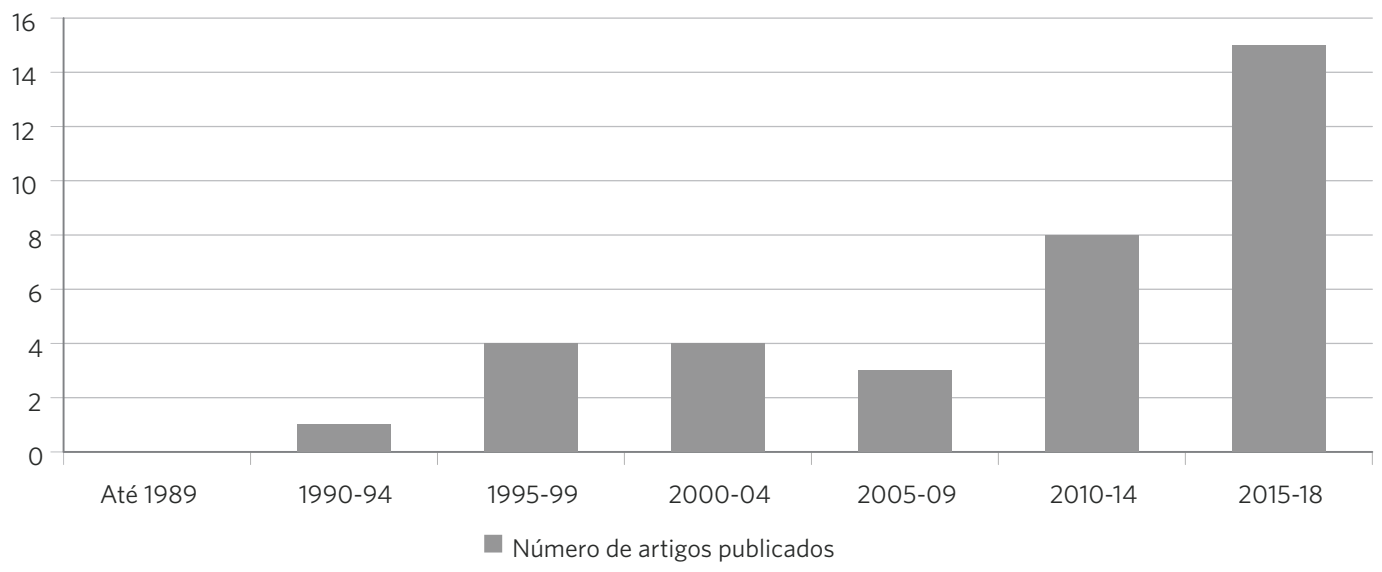

Fonte: Elaboração própria.

Em termos de veículos de publicação, chama a atenção a pulverização desses estudos em diversas revistas. A maior parte dos artigos foi publicada em revistas da área de 'ciências humanas'(18) 17-34, vindo em segundo lugar, curiosamente, a área de 'ciências da saúde' $(8)^{35-42}$, sendo a revista 'Ciência e Saúde Coletiva' a que mais publicou(3) ${ }^{36-38}$. Essa concentração é coerente com o perfil dos autores principais, uma vez que todos os artigos publicados em revistas de 'ciências humanas' foram produzidos por pesquisadores que atuam nessa 'grande área'. Situação similar ocorre nas revistas de 'ciências agrárias'(2) ${ }^{\mathbf{4 3}, 44}$; e, no caso das revistas de 'ciências sociais aplicadas'(5) ${ }^{45-49}$, apenas um autor é proveniente das 'ciências humanas'48. Além desses, foram identificados dois artigos publicados em revistas consideradas 'interdisciplinares', um de autor da 'linguística'50 e outro de autora das 'ciências da saúde'51. No caso dos artigos publicados em revistas de 'ciências da saúde', os autores principais provêm de diversas áreas (fonoaudiologia ${ }^{35}$, terapia ocupacional ${ }^{36}$, história ${ }^{37}$, filosofia ${ }^{38}$, enfermagem ${ }^{39}$, odonto$\operatorname{logia}{ }^{40}$, fisioterapia ${ }^{41}$ e medicina ${ }^{42}$ ), embora todos tenham formação pós-graduada e/ou atuação na área de saúde pública/coletiva.

Essa situação revela plena sintonia entre 
as áreas dos autores e revistas, mas, ao mesmo tempo, em muitos casos, pode revelar limites para romper fronteiras disciplinares. No caso da saúde, porém, ocorre uma dinâmica um pouco diferenciada, pois foi notado tanto o interesse, por parte de pesquisadores das 'ciências da saúde', em acionar referenciais das 'ciências humanas e sociais' quanto a preocupação de pesquisadores de outras áreas com questões de saúde. Uma hipótese a ser considerada nesse caso é o fato da 'saúde coletiva' se constituir a partir da articulação de construções teórico-metodológicas de diferentes áreas do conhecimento e favorecer esses diálogos.

\section{O que é conjuntura? $O$ que é análise de conjuntura?}

A grande maioria dos artigos não apresenta definição de 'conjuntura' ou 'análise de conjuntura', e essa situação também é verificada entre os cinco artigos que se propõem a desenvolver elementos teórico-conceituais. Entre todos os artigos analisados, apenas um $^{30}$ propõe uma definição de conjuntura, os demais referem-se a autores que abordam noções e conceitos que subsidiam esse tipo de análise.

Rojas $^{32}$, por exemplo, cita Gramsci, enfatizando a diferenciação entre os 'movimentos orgânicos', que seriam 'relativamente permanentes' e teriam 'grande alcance histórico', e os 'movimentos conjunturais', que poderiam

[...] levar a algumas crises cíclicas, onde se questionem os governos, as políticas ou se realize uma crítica particular, mas tem um menor alcance histórico ${ }^{32(226)}$.

Percebe-se que essa construção destaca o 'alcance histórico' de determinados acontecimentos. Nessa perspectiva, Rodrigues ${ }^{\mathbf{3 0}}$ reafirma a relação dinâmica entre estrutura e conjuntura, comentando que a estrutura pode ser transformada a depender da evolução dos conflitos conjunturais. Para ele,
[...] a conjuntura é um 'momento' [grifo nosso] de um processo político mais longo, balizado por certos parâmetros políticos (e econômicos, sociais, culturais, ideológicos etc) estruturados, no qual determinados atores, portadores de recursos e estratégias, confrontam-se conflitivamente em torno de arenas e agendas específicas, com vistas à obtenção de certos resultados ${ }^{30(104)}$.

Magno e Paim51, por sua vez, focam em explicitar o que seria analisar uma conjuntura. Essa é uma abordagem que implicaria

[...] examinar o desenvolvimento desigual das relações de força em cada um dos níveis que compõem o social, determinado por múltiplas relações, como um produto de atores sociais que se opõem e possuem distintos graus de organização e coerência51(3).

Além dessas concepções de caráter mais político, focadas no conflito e na correlação de forças entre atores sociais em um determinado momento, outros dois artigos $\mathbf{4 4 , 4 9}$ tratam de aspectos da 'conjuntura econômica', analisada a partir do acompanhamento de indicadores econômicos, delimitados a um espaço geográfico, no caso desses estudos, um município ${ }^{49}$ e um estado ${ }^{44}$. Esse tipo de abordagem também busca elaborar projeções que subsidiem decisões dos diversos "agentes econômicos"49(304).

Nos demais artigos, mesmo sem explicitações conceituais, foram encontradas diversas 'adjetivações' vinculadas ao termo conjuntura, que remetem a alguns tipos de recorte, em um esforço de delimitação do objeto de análise, e que também estão relacionadas com o perfil do pesquisador. Assim, encontram-se termos que indicam recorte espacial ('internacional'20, 'externa'45, 'brasileira'27, 'socioespacial'25) e/ou temporal ('histórica'26,31,48; 'histórica presente'29, 'atual'36,45, 'contemporânea'33,37, 'recente'51), assim como temático ('política'21,26,31,35,38,41,51, 'econômica'44,47,49, 'social'26,34, 'socioeconômica'41, 
'ideológica'18, 'agrária'26, 'eclesial'29, 'religiosa'23, 'religioso-eclesial'23, 'sócio-religiosa'23, 'eleitoral'17, 'epidemiológica'39). Além disso, chama a atenção, em alguns artigos, a explicitação clara do posicionamento dos autores com relação à conjuntura analisada, denominada por alguns de 'adversa'51 ou 'conflitiva'30, o que denota uma contraposição aos interesses que movem os autores da análise.

\section{Quais os possíveis recortes tem- porais e espaciais em análises de conjuntura?}

A análise dos diversos artigos evidencia, em primeiro lugar, que muitos não explicitam critérios para a delimitação do tempo coberto pela análise de conjuntura. No caso dos estudos de 'conjuntura econômica'44,46,47,49 e de 'conjuntura epidemiológica'39,40, por exemplo, a definição temporal teve relação direta com os períodos de publicação dos dados utilizados como referência, sem especificação de fatos ou acontecimentos que demarcariam 'pontos de corte'. Outros, entretanto, fazem referência a determinados 'tempos políticos', vinculados a mudanças de governos ${ }^{\mathbf{2 6}, \mathbf{4 5}}$, a momentos de transição ${ }^{24,29,30,51}$, à eclosão de crises ${ }^{17,32}$ ou a processos que extrapolam esses períodos ${ }^{28,35,38}$, mas os tomam como referência. Uma terceira forma de delimitação temporal aparece em alguns artigos que tomam como ponto de partida para a análise da conjuntura um único fato ou acontecimento e suas implicações históricas e/ou sociais 19,21,22,33,48.

Percebe-se, portanto, três formas distintas de lidar com o tempo, quer seja delimitado a partir de uma cronologia (tempo cronológico), estabelecida previamente, quer seja delimitado a partir de processos políticos que possibilitariam algum tipo de periodização (tempo político), ou a partir de um fato com consequências políticas que se estendem no tempo.

Com relação ao recorte espacial, constata-se também uma diversidade de possibilidades, que dizem respeito ao território tomado como espaço no qual ocorrem os fatos, acontecimentos e processos analisados pelos diversos autores. Assim, encontraram-se artigos que analisam a 'conjuntura internacional', enfatizando a análise das relações entre países, seja com objetivo de identificar "tendências de longo prazo"20(131), seja de problematizar aspectos relacionados com a política e com o direito internacional22. Também se encontraram artigos que enfatizam a análise da conjuntura brasilei-

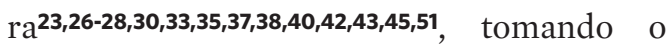
espaço nacional como referência, enquanto outros delimitam seus recortes a estados ${ }^{\mathbf{4 4}}$, microrregiões ${ }^{36}$, municípios ${ }^{34,39,47,49}$ ou desenvolvem suas análises a partir de instituições como a "Igreja católica"29(1383). Cabe destacar que alguns artigos dedicaram atenção específica para duas ou mais dessas dimensões espaciais, como os artigos de Rojas $^{32}$, que faz uma "caracterização dos governos petistas"32(228) e, em seguida, discute 'hegemonia' e 'dominação’ no âmbito mundial, e o de Béjar ${ }^{17}$, que dedica uma parte do texto para analisar elementos da 'economia internacional', para em seguida enfocar elementos da economia e da política mexicana.

Além de artigos com recortes delimitados, foi possível localizar também estudos que desenvolvem comparações a partir de indicadores econômicos em diferentes municípios ${ }^{46}$ ou a partir de temas como a exploração da matriz eólica ${ }^{25}$ ou as desigualdades e o racismo em países distintos $^{24}$. Um outro artigo, que é desenvolvido a partir da trajetória de um ator, acaba relatando fatos ocorridos em diferentes localidades, mas que em alguns momentos se conectam com a dimensão nacional ${ }^{31}$.

Cabe comentar que, apesar da delimitação de recortes espaciais, percebe-se, nas análises apresentadas nos artigos, a indicação da existência de inter-relações entre esses diversos espaços, sem que, entretanto, a maioria dos autores desenvolva problematizações a esse respeito. 


\section{Quais os referenciais teóricos explici- tados nos estudos?}

Poucos artigos citam de forma explícita referenciais teóricos voltados para a realização de análises de conjuntura. Alguns desenvolvem apenas discussões teóricas sobre as categorias relacionadas com os temas específicos que são utilizadas no processo analítico de cada artigo. Um terceiro grupo de autores opta por não aprofundar discussões teóricas.

Dos que apresentam ou problematizam conceitos e referenciais, foi possível identificar várias vertentes, de acordo com a filiação dos autores a determinadas tradições no âmbito das 'ciências humanas e sociais'52. Nesse sentido, quatro estudos citam explicitamente referenciais 'marxianos'20,32,41,51, um utiliza conceitos extraídos da obra de Weber ${ }^{29}$, dois vinculam-se ao institucionalismo' 24,46, um recorre a Bourdieu ${ }^{\mathbf{3 1}} \mathrm{e}$ um referencia Michel Dobry ${ }^{30}$. Além desses, um estudo de 'conjuntura econômica' cita referenciais dessa área ${ }^{49}$.

Entre os artigos que explicitam 'referências marxianas', encontra-se Rojas ${ }^{32}$, que cita obras de Marx e Engels, a exemplo de 'O Capital', 'O 18 Brumário de Luís Bonaparte' e 'O Manifesto do Partido Comunista', bem como obras de Lenin, a exemplo do 'Imperialismo, fase superior do capitalismo’. Além disso, incorpora a contribuição de Poulantzas, afirmando utilizar "os conceitos teóricos classe, fração de classe e bloco no poder"32(228) discutidos em 'As classes sociais no capitalismo hoje'. Ademais, cita a diferenciação entre "movimentos orgânicos" e "conjunturais"32(226) apresentada nos 'Cadernos do Cárcere' de Gramsci.

Nessa perspectiva, Magno e Paim ${ }^{51}$ também se apoiam em Gramsci e acionam categorias de análise propostas por Souza 53 para desenvolver sua análise da conjuntura política em saúde em um período que vai das 'Jornadas de Junho de 2013' até os primeiros meses do segundo mandato de Dilma Rousseff.
Já Souza et al.41, em artigo sobre relações de trabalho, afirmam, em tópico específico sobre a 'conjuntura socioeconômica', tomar

[...] como referencial teórico a abordagem marxista que aponta as causas das relações de trabalho - entendendo-as como fruto da correlação dos determinantes socioeconômicos vinculados às condições de trabalho41(1306).

Cabe destacar que, em outros tópicos da discussão, os autores utilizam também conceitos de autores como Weber e Bourdieu.

No caso de Fiori ${ }^{20}$, a análise desenvolvida faz referência a "três grandes escolas de pensamento da economia política: a teoria do imperialismo, a teoria da 'hegemonia mundial' e a teoria do world-system" 20(139), mas afirma que sua "leitura da história", o levou "a algumas conclusões diferentes desses autores"20(139). Algumas dessas vertentes dialogam com 'autores marxianos'; e Fiori faz referência, especificamente, a Lenin ao indicar seu vínculo com a primeira abordagem citada.

$\mathrm{O}$ autor que referencia Weber é Passos²9, que direciona seu olhar para a análise de uma instituição: a 'Igreja católica'. Para isso, utiliza "como referência os tipos weberianos de poder legítimo - dominação carismática, dominação tradicional e dominação burocrática" e, com base neles, afirma analisar a "conjuntura eclesial atual"29(1384).

Entre os artigos vinculados ao 'institucionalismo', é possível citar Leubolt24, que, apesar de referenciar $\operatorname{Souza}^{53}$ e Fiori para realizar a análise de conjuntura, afirma partir do "institucionalismo estratégico-relacional"24(51), levando em consideração a "formação discursiva e a institucionalização do regime de desigualdades"24(51) nos países analisados. O outro, de Oliveira e Piffer ${ }^{46}$, também se utiliza do referencial "institucionalista, tendo como expoente os trabalhos de North sobre a Base de Exportação e o Ambiente Institucional"46(32), e aborda "o conceito de desenvolvimento 
territorial”46(34) para realizar suas análises.

O referencial de Bourdieu é acionado por Fabiana Rodrigues ${ }^{31}$, mas seu foco se volta para fatos do passado, a partir de uma análise de "conjuntura histórica"31(43) e do acompanhamento da trajetória de um ator.

Já Alberto Rodrigues ${ }^{\mathbf{3 0}}$ destaca

[...] o modelo de análise de conjunturas fluidas, isto é, conjunturas de crise política conjugadas, no correr do curto prazo, a amplos processos de mobilização de massa, desenvolvido por Michel Dobry30(105).

Entre os artigos de 'conjuntura econômica', identificou-se o de Zirene e Zapara ${ }^{49}$, o qual cita diversos autores da área e, a partir deles, tanto apresenta aspectos metodológicos como problematiza os teóricos. Ao citar que o foco desse tipo de análise está relacionado com o acompanhamento de variáveis econômicas, problematiza diferenças analíticas entre a dimensão micro e macroeconômica, bem como de análises globais e parciais, considerando que mesmo as análises parciais que se utilizam de variáveis pontuais precisam estar articuladas com os resultados obtidos em análises globais.

Santos et al. ${ }^{33}$ afirmam utilizar "a sociologia dos atores e leituras pós-coloniais, duas vertentes de interpretação das relações internacionais"33(88), mas sem explicitar autores de referência ou aprofundar elementos teórico-conceituais a respeito dessas vertentes.

Cabe destacar que, em estudos considerados de 'conjuntura política' e não limitados ao âmbito setorial, prevaleceu o 'referencial marxiano'. É importante reafirmar que autores como Bourdieu e Weber foram utilizados em situações especiais, o primeiro em um estudo que direciona seu olhar para a trajetória de um ator no passado ${ }^{31}$ e o segundo em investigação que se restringe a analisar aspectos limitados a uma instituição ${ }^{29}$.

Como foi possível observar, diversos referenciais foram utilizados para subsidiar análises de conjuntura, os quais estão diretamente relacionados com as escolhas temáticas e com os recortes espaciais e temporais utilizados pelos autores. Essa coerência precisa ser levada em consideração, inclusive, para pensar se 'análise de conjuntura' é a melhor denominação a usar, independentemente do referencial e do tipo de estudo a ser desenvolvido. Diante dos aspectos assinalados, é importante considerar quais seriam as possíveis intenções do autor ao filiar-se a estudos de análise de conjuntura, uma vez que o uso desta expressão em certas circunstâncias poderia ser um mero 'descuido teórico-conceitual'. Será que há alguma intencionalidade não explicitada, por exemplo, algum tipo de implicação política com o objeto de estudo?

\section{Quais as estratégias metodológi- cas para realização de análises de conjuntura?}

A maioria dos artigos foi desenvolvida a partir do acompanhamento de fatos e acontecimentos, especialmente no caso dos estudos que deram mais ênfase à dimensão políti$\mathrm{ca}^{17,20-22,24-27,30-33,35,36,38,41,42,45,51}$ contemporânea, ou do acompanhamento de índices, variáveis e indicadores como nos estudos com enfoques econômicos $4 \mathbf{3}, \mathbf{4 4 , 4 6 , 4 7 , 4 9}$, sociais $^{34}$ e epidemiológicos ${ }^{39,40}$. Isso não significa que estes últimos são compostos por trabalhos estritamente quantitativos. Alguns deles também se apoiaram em análises qualitativas, inclusive ao problematizar a relação com aspectos políticos e sociais. Muitos estudos focados na 'conjuntura política' também fundamentaram suas análises em dados quantitativos a partir do uso de indicadores econômicos, situação que demonstra a importância de conhecer as diversas abordagens de análise conjuntural para identificar como os diferentes métodos utilizados podem se complementar em estudos que tenham o propósito de construir uma análise mais abrangente. Afinal, mesmo que eles partam de um tema específico e se 
proponham a assumir um recorte setorial, é preciso considerar as influências dos aspectos políticos, econômicos, sociais e culturais, o que conduz à possibilidade de integração metodológica, superando a distinção quantitativo-qualitativo ${ }^{54}$.

As principais fontes de informação na maioria dos artigos são derivadas de pesquisa documental, tais como: notícias extraídas de jornais, revistas e/ou mídias digitais $\mathbf{2 1}^{2} \mathbf{4 8 , 5 1}$, periódicos e panfletos políticos ${ }^{28}$, atas de reuniões ${ }^{26}$, programas de governo ${ }^{51}$, documentos produzidos por órgãos públicos ${ }^{34,36,37}$ e por outras instituições e seus representantes, como 'igreja' ${ }^{18,29}$ e 'entidades de saúde'51. Foram utilizados também dados produzidos por órgãos como Instituto Brasileiro de Geografia e Estatística (IBGE) $\mathbf{2 3 , 3 4 , 4 4 , 4 6 , 4 7}$, Instituto de Pesquisa Econômica (Ipea) ${ }^{\mathbf{4 6}}$, Programa das Nações Unidas para o Desenvolvimento (PNUD) ${ }^{40,46}$, Banco Central (BCB $)^{44}$, Instituto Paranaense de Desenvolvimento Econômico e Social (Ipardes) ${ }^{47}$, Federação das Indústrias do Estado do Rio de Janeiro (Firjan) ${ }^{47}$, Associação Brasileira de Alumínio $(\mathrm{Abal})^{37}$ ou publicizados em relatórios de secretarias $^{44}$ e ministérios de governo ${ }^{40,46}$. Foi citada também a utilização de bases de dados específicas, a exemplo dos sistemas de informação na área de Saúde, como o Sistema de Informação de Agravos de Notificação $\left(\right.$ Sinan) ${ }^{39}$ e Sistema de Informação Ambulatorial do SUS (SIA/SUS)40. Contudo, muitos dos artigos não informam se houve acompanhamento sistemático de alguma dessas fontes de informação. Em alguns artigos, além da pesquisa documental, informações foram produzidas a partir de entrevistas ${ }^{36,41,47}$ ou por meio de observação $0^{26}$ e registro de processos políticos ocorridos no âmbito de determinadas instituições ou movimentos sociais relacionados com o tema estudado.

Para o caso de estudos de 'análise política em saúde', esse levantamento dá uma dimensão das variadas fontes que podem ser utilizadas para acompanhamento de 'fatos políticos' e 'indicadores econômicos e sociais' e, ao mesmo tempo, evidencia a importância de que, em estudos científicos, sejam claramente explicitadas as fontes de informação, critérios de seleção e o período de acompanhamento, visto que, em muitos dos artigos analisados nesta revisão, esses elementos não foram explicitados.

Naquilo que se refere à análise, a maioria dosestudos optou por desenvolvê-la combase em categorias e indicadores apenas citados ou problematizados a partir de referenciais teóricos vinculados ao tema de estudo. Entre esses, foi possível notar tanto estudos que desenvolviam interpretações a partir de categorias aplicadas a um determinado recorte espacial e temporal17-22,26-33,36,38,41,42,48,51 quanto estudos que propuseram comparações entre locais diferentes $\mathbf{2 4 , 2 5 , 4 0 , 4 3 , 4 6}$, períodos diferentes ${ }^{23,24,37,39,43-47}$, setores diferentes (da economia) ${ }^{49}$ ou com base em características demográficas e socioeconômicas $^{34,40}$. Cabe destacar que praticamente todos os estudos citaram a influência de fatos que extrapolavam a dimensão setorial ou o recorte espacial e temporal, sendo que a maioria apresentou antecedentes históricos relacionados com o tema em estudo.

Além disso, cabe chamar atenção para dois grupos de estudos. Alguns artigos que tratam do passado seguiram as mesmas lógicas de artigos sobre 'conjunturas recentes' ao definir período ou fato de referência, propor demarcação espacial, explicitar elementos que envolvem a correlação de forças entre atores e fazer a relação com aspectos estruturais. Contudo, por serem fatos ocorridos muitos anos antes da análise, essa abordagem, isoladamente, não oferece os subsídios necessários para a ação imediata, apesar de trazer contribuições a partir da experiência histórica. Por outro lado, alguns estudos que tratam de períodos recentes, com as mesmas preocupações com delimitação temporal e espacial, discutiram apenas dados produzidos sobre o tema indicado, mas sem considerar situações de conflito que levaram àquela 
situação nem aprofundar conexões com elementos globais e macroestruturais.

Essas análises, focadas apenas no âmbito local e setorial, podem acabar limitando-se a uma mera caracterização que apresenta evidências referentes ao tema estudado, mas, ao não problematizar relações de cooperação e/ ou conflitos entre atores, nem a relação entre estrutura e conjuntura, também limitam seu potencial de ação já que podem partir de uma racionalidade técnica que desconsidera elementos políticos, econômicos, sociais e culturais. Ambas as propostas de estudos se distanciam do que autores como Souza ${ }^{53}$ consideram que seria e como se desenvolveria uma análise de conjuntura, sendo possível problematizar se a denominação de 'análise conjuntural' é a melhor a ser empregada.

\section{Análises de conjuntura na área da saúde}

Nas análises aplicadas ao setor saúde, houve mais detalhamento teórico e/ou metodológico, sendo que a maioria buscou conectar a dimensão setorial com elementos histórico-estruturais que incidem sobre os fatos em análise. Desse modo, foram identificados tanto estudos de caráter político e conectados com a dimensão macroestrutural que dialogam com o 'processo e o projeto da Reforma Sanitária Brasileira'55 quanto análises que focam em recortes mais específicos, inclusive abordagens que foram denominadas de análise de "conjuntura epidemiológica"39(18).

Entre os artigos que desenvolvem sua análise a partir de categorias que extrapolam o setor saúde está o de $\mathrm{Luz}^{38}$, que discute a relação entre 'centralização/descentralização' das políticas de saúde e processos de "concentração de poder social na sociedade brasileira"38(293) e, portanto, evidencia os impactos na saúde de elementos de ordem estrutural e política. Um outro artigo que não se limita ao setorial é o de Magno e Paim ${ }^{51}$, em que é proposta uma análise da conjuntura de 2013 a 2015, com atenção especial para o 'processo da Reforma Sanitária
Brasileira' (RSB), e se apoia nas categorias apresentadas por Souza ${ }^{53}$ : 'fatos', 'cenários' e 'relação de forças'.

Esses dois artigos ancoram-se em aspectos sociais, econômicos e políticos amplos, pontuando, inclusive, conexões com atores internacionais. Dessa maneira, seus recortes não se limitaram ao setor saúde. São exemplos que demonstram a conexão direta entre os fatos da conjuntura e as políticas de saúde, e como grupos com mais capacidade de intervenção conseguem fazer progredir certas pautas.

Outros dois artigos ${ }^{35,41}$ aproximam-se bastante da abrangência de análise dos anteriores, já que acionam várias dimensões da análise conjuntural. Contudo, apresentam uma diferença que merece ser destacada, qual seja: a análise parte da atuação de um profissional de saúde para discutir a influência do Estado e o modo de produção econômica nas práticas de saúde. $\mathrm{O}$ artigo de Souza et al. ${ }^{41}$ direciona sua atenção para o trabalho de fisioterapeutas com atuação no setor privado e discute os impactos da "conformação do Estado neoliberal" e da "precarização do mundo do trabalho" 41(1301) na área da saúde, gerando instabilidade, aumento do desemprego e flexibilização de direitos. Nessa mesma linha, Bazzo ${ }^{35}$ relaciona a "incipiente oferta de fonoaudiólogos nos serviços públicos de saúde" com aspectos da "conjuntura política" decorrentes, especialmente, da "reforma do Estado brasileiro"35(190), imposta por agências internacionais em meados da década de 1990, com repercussões para as políticas de saúde.

Um quinto artigo, de Cotta et al. ${ }^{36}$, parte de um recorte mais delimitado e discute como os processos de privatização no sistema de saúde decorrem da "maneira desorganizada de o governo implementar a Reforma Sanitária"36(94), citando que esses processos ocorrem de maneira semelhante em "outras esferas da sociedade brasileira"36(95) e se dão por consequência da ação/omissão de governos. Circunscreve a discussão basicamente a aspectos relacionados com o setor saúde a 
partir de investigação empírica em uma microrregião mineira. Portanto, não aprofunda os elementos externos ao setor saúde nem analisa os atores em disputa.

Esse pode ser um limite dos estudos setoriais de âmbito local, em especial sobre o setor público de saúde, uma vez que o sistema é estruturado a partir de dinâmicas que interconectam os níveis municipal, estadual e federal, sendo regido pela Constituição e por leis de âmbito nacional. $\mathrm{Na}$ análise de processos como a privatização do sistema, também é importante considerar fatores estruturais, como a ação do capital financeiro internacional sobre o setor analisado ${ }^{56}$.

Entre os artigos de caráter epidemiológico, é possível citar o de Silva et al.40, que se propõe a "analisar a conjuntura nacional referente ao perfil epidemiológico do edentulismo"40(121), discutindo sua relação com aspectos sociais, culturais e econômicos, bem como com o "modelo de prática odontológica hegemônico"40(123). Apesar de ter como objetivo a 'análise de conjuntura', a abordagem tem características particulares, pois apresenta uma caracterização do problema, mas não aprofunda as análises sobre fatos e correlações de forças que contribuíram para a situação problematizada, tampouco seus antecedentes.

A mesma situação ocorre com o artigo de Matos et al. ${ }^{39(18)}$ que se propõe a "analisar a conjuntura epidemiológica da hanseníase" por meio de um "estudo de caráter quantitativo e retrospectivo de uma série de casos de menores de 15 anos"39(18) de maneira a caracterizar, especialmente, frequência, modo de detecção e forma clínica. Demonstra a importância de conhecer a dinâmica epidemiológica para desenvolver ações de enfrentamento de problemas como a hanseníase, mas desconsidera outros elementos essenciais na compreensão dos determinantes de sua incidência e prevalência, que estão relacionados, inclusive, com a omissão ou intervenção do Estado.

Por último, o artigo de Henriques e Porto ${ }^{37(3223)}$ discute os "impactos socioambientais e à saúde pública" decorrentes da produção de alumínio, em especial, a partir da inserção do Brasil no mercado mundial, como parte de uma "nova configuração da Divisão Internacional do Trabalho"37(3223), em que atividades mais poluentes e que demandam mais energia passariam a ser deslocadas para países periféricos. Esse artigo também poderia ser classificado como de conjuntura econômica, mas, apesar de discutir elementos relacionados com um setor produtivo, desenvolve análises que se articulam com aspectos ambientais e de saúde.

Como foi possível observar, os estudos de conjuntura focados no setor saúde possuem variadas formas de aplicação e podem tratar de aspectos específicos, mas sem desconsiderar sua relação direta com outras dimensões de análise. Os estudos de caráter epidemiológico assumem características muito parecidas com 'análises de conjuntura econômica', já que delimitam períodos cronologicamente, trabalham com indicadores, não explicitam claramente referenciais teóricos e direcionam mais atenção ao percurso metodológico. Vale destacar que a análise da situação epidemiológica pode oferecer diversos dados e informações que alimentam estudos mais aprofundados de análise de conjuntura relacionados com o setor saúde. Contudo, na 'análise política em saúde', é importante que pesquisadores consigam conectar análises específicas com as de âmbito estrutural, pois, em conjunto, apresentam um potencial mais amplo para contribuir para a ação transformadora.

\section{Considerações finais}

Conforme observado, não há um referencial comum acionado ao se propor análises de conjuntura, apesar de ter sido mais citado o 'referencial marxiano'. Merece atenção o fato de a maioria dos artigos revisados não se preocupar em explicitar ou problematizar seus referenciais teóricos, 
conceituais ou metodológicos, situação que evidencia certa 'rarefação teórica'57 em muitos dos estudos revisados.

Naquilo que se refere aos aspectos metodológicos, as 'análises de conjuntura' apresentam diversas abordagens, sendo que as opções assumidas pelos autores estão relacionadas com o tema, com as escolhas teóricas e com os recortes espaciais e temporais definidos. Apesar de não ter sido observado um percurso metodológico único, no caso específico das análises que aprofundam aspectos políticos, foi possível perceber o interesse em identificar fatos relevantes e relações de cooperação e/ou conflito entre os atores. Em alguns deles, as análises apoiaram-se em indicadores econômicos e sociais, consideraram antecedentes históricos e, em casos mais específicos, discutiram tendências futuras.

Todos os artigos do setor saúde, por sua vez, citam a relação entre o setorial e outras dimensões da conjuntura, sendo que alguns aprofundam essas conexões, mas fica evidente que, para desenvolver esse tipo de abordagem aplicada à 'análise política em saúde', é necessário se debruçar sobre uma ampla produção teórica que discute 'o poder', 'o político', 'os atores/sujeitos' e 'a ação'.

Percebe-se, portanto, que a análise de conjuntura é uma abordagem com importantes contribuições para os estudos de 'análise política em saúde', porém, é necessário que os aspectos teórico-metodológicos não sejam negligenciados, levando em consideração a natureza do tema, os possíveis recortes, as teorias acionadas e os procedimentos adotados, de modo a alcançar uma adequada compreensão da totalidade complexa na qual estão imersos os fatos e processos históricos tomados como objeto destas análises.

Por fim, cabe enfatizar que a realização de uma apurada análise de conjuntura não garante os resultados esperados para a práxis política, mas quanto melhor elaborada for, melhores serão os subsídios para ações transformadoras. Os embates se dão em meio à ação de diversos atores; e a análise contribui, justamente, para subsidiar escolhas teóricas, metodológicas, políticas e técnicas.

\section{Colaboradores}

Virgens JHA contribuiu para as seguintes atividades: 1) concepção, planejamento, análise e interpretação dos dados; 2) revisão do texto do artigo; e 3) aprovação da versão final do manuscrito. Teixeira CF contribuiu para as seguintes atividades: 1) concepção e planejamento; 2) revisão do texto do artigo; e 3) aprovação da versão final do manuscrito.

\section{Agradecimentos}

Ao grupo do Eixo 'Análise do Processo da Reforma Sanitária Brasileira no Período 2007 a 2016' do Observatório de Análise Política em Saúde (OAPS), coordenado pelo prof. Jairnilson Paim e pela prof. ${ }^{a}$ Carmen Teixeira, pelas oportunidades de diálogo sobre o tema do artigo. À Tarsila Figueiredo por contribuir para a elaboração deste artigo com a revisão do texto e com a tradução do resumo. 


\section{Referências}

1. Paim JS. Posfácio. Análise política em saúde: um pensamento estratégico para a ação estratégica. In: Federico L. Análise política em saúde: a contribuição do pensamento estratégico. Salvador: Edufba; 2015. p. 279-286.

2. Teixeira CF. Produção Científica na Área de Política, Planejamento e Gestão em Saúde 1975-2010. In: Baptista TWF, Azevedo CS, Machado CV. Políticas, planejamento e gestão em saúde: abordagens e métodos de pesquisa. Rio de Janeiro: Fiocruz; 2015. p. 81-111.

3. Paim JS, Teixeira CF. Política, planejamento e gestão em saúde: balanço do estado da arte. Rev Saúde Pública [internet]. 2006 ago [acesso em 2017 jun 7]; 40(esp):73-78. Disponível em: http://www. scielo.br/pdf/rsp/v40nspe/30625.

4. Santos JS, Teixeira CF. Política de saúde no Brasil: produção científica 1988-2014. Saúde debate [internet]. 2016 mar [acesso em 2017 jun 7]; 40(108):219-230. Disponível em: http://www.scielo.br/scielo.php?script=sci_arttext\&pid=S0103$-11042016000100219 \& \operatorname{lng}=$ en\&nrm=iso.

5. Baptista TWF, Azevedo CS, Machado CV. Políticas, planejamento e gestão em saúde: abordagens e métodos de pesquisa. Rio de Janeiro: Fiocruz; 2015.

6. Teixeira CF, Silveira P, organizadores. Glossário de análise política em Saúde. Salvador: Edufba; 2016.

7. Moreira MS. Em busca de uma metateoria: análise de conjuntura, ciência e política a partir dos textos sobre as jornadas de junho. In: Anais do $10^{\circ}$ Encontro da Associação Brasileira de Ciência Política [internet]. 2016 set 1. Belo Horizonte: ABCP; 2016. Disponível em: https://cienciapolitica.org. br/system/files/documentos/eventos/2017/04/ analise-conjuntura-ciencia-e-historia-investigacao-sobre.pdf.
8. Cruz SCV. Teoria e método na análise de conjuntura. Educ Soc [internet]. 2000 ago [acesso em 2018 maio 16]; 21(72):145-152. Disponível em: http://www.scielo.br/scielo.php?script=sci arttext\&pid=S0101-73302000000300008\&lng=e $\mathrm{n} \& \mathrm{nrm}=$ iso.

9. Lopes ALM, Fracolli LA. Revisão sistemática de literatura e metassíntese qualitativa: considerações sobre sua aplicação na pesquisa em enfermagem. Texto Contexto Enferm [internet]. $2008 \mathrm{dez}$ [acesso em 2018 maio 15]; 17(4):771-778. Disponível em: http://www.scielo.br/scielo.php?script=sci arttext\&pid=S0104-07072008000400020\&lng= en\&nrm=iso.

10. Gomes I, Caminha I. Guia para estudos de revisão sistemática: uma opção metodológica para as Ciências do Movimento Humano. Movimento [internet]. 2014 jan-mar [acesso em 2018 maio 15]; 20(1):395-411. Disponível em: http://www.seer.ufrgs.br/Movimento/article/viewFile/41542/28358.

11. Sampaio RF, Mancini MC. Estudos de revisão sistemática: um guia para síntese criteriosa da evidência científica. Rev Bras Fisioter [internet]. $2007 \mathrm{fev}$ [acesso em 2018 maio 15]; 11(1):83-89. Disponível em: http://www.scielo.br/scielo.php?script=sci arttext\&pid $=$ S1413-35552007000100013\&lng=en $\&$ nrm $=$ iso.

12. Rother ET. Revisão sistemática X revisão narrativa. Acta Paul Enferm [internet]. 2007 jun [acesso em 2018 maio 15]; 20(2):5-6. Disponível em: http://www.scielo.br/scielo.php?script=sci arttext\&pid=S0103-21002007000200001\&lng=e $\mathrm{n} \& \mathrm{nrm}=\mathrm{iso}$.

13. Turolla FA, Lima MFF, Margarido MA. Notas sobre a prática dos economistas de mercado no brasil. São Paulo Perspec [internet]. 2009 jul-dez [acesso em 2018 maio 16]; 23(2):18-27. Disponível em http://produtos.seade.gov.br/produtos/spp/ v23n02/v23n02_02.pdf. 
14. Mendonça Filho M, Vasconcelos MFF. Questões de método e pesquisa dos dispositivos institucionais de confinamento do presente. Estud Pesq Psicol [internet]. 2010 jan-mar [acesso em 2018 maio 16]; 10(1):134-150. Disponível em: http://www.revispsi.uerj.br/v10nl/artigos/pdf/v10nlalo.pdf.

15. Wiese ML. A discussão do social no âmbito da prática profissional. Rev Soc Cardiol [internet]. 2011 out-dez [acesso em 2018 maio 16]; 21(supl.4):3438. Disponível em: http://nisfaps.paginas.ufsc.br/ files/2014/09/Artigo-A-Discuss\%C3\%A3o-do-Social-no-\%C3\%82mbito-da-Pr\%C3\%Altica-Profissional-Rev-SOCESP.pdf.

16. Barbosa I, Ferreira FI. Teatro do Oprimido e projeto emancipatório: mutações, fragilidades e combates. Soc Estado [internet]. 2017 ago [acesso em 2018 maio 16]; 32(2):439-463. Disponível em: http://www.scielo.br/scielo.php?script=sci arttext\&pid=S0102-69922017000200439\&lng=e $\mathrm{n} \& \mathrm{nrm}=\mathrm{iso}$.

17. Bejar AA. México: contexto econômico e estratégias eleitorais. Lua Nova [internet]. 2000 [acesso em 2018 maio 16]; 49:161-174. Disponível em: http://www.scielo.br/scielo.php?script=sci arttext\&pid=S0102-64452000000100009\&lng=e s\&nrm $=$ iso

18. Coelho RT. A tradição judaico-cristã e a homofobia: substratos ideológicos de um preconceito. Cad Gênero Diversidade [internet]. 2015 [acesso em 2018 maio 16]; 1(1):162-80. Disponível em: https://portalseer.ufba.br/index.php/cadgendiv/article/view/13945.

19. Ferabolli SR. Uma nova visão para a regionalização do mercado de trabalho árabe. Rev Conjuntura Austral [internet]. 2016 [acesso em 2018 maio 16]; 7(36):5-11. Disponível em: http://seer.ufrgs.br/index.php/ConjunturaAustral/article/view/65599.

20. Fiori JLC. Prefácio ao poder global. Rev Tempo Mundo [internet]. 2010 abr [acesso em 2018 maio 16]; 2(1):131-153. Disponível em: http://www.ipea.
gov.br/portal/images/stories/PDFs/rtm/100923_ rtm_port02_cap6.pdf.

21. Guimaraes ASA. Ação afirmativa, autoritarismo e liberalismo no brasil de 1968. Novos Estud CEBRAP [internet]. 2015 jan-mar [acesso em 2018 maio 16]; (101):5-25. Disponível em: http://www. scielo.br/scielo.php?script=sci_arttext\&pid=S0101$-33002015000100005 \& \operatorname{lng}=\mathrm{en} \& \mathrm{nrm}=$ iso.

22. Ide D. O mandado de prisão do TPI contra Al-Bashir à luz da relação entre poder e moral internacionais. Meridiano 47 [internet]. 2009 [acesso em 2018 maio 16]; 10(105):30-33. Disponível em: http://periodicos.unb.br/ojs311/index.php/MED/ article/view/3616.

23. James C. Análise de conjuntura religioso-eclesial. Perspectiva Teológica [internet]. 1996 jan [acesso em 2018 maio 16]; 28(75)1-26. Disponível em: http://www.faje.edu.br/periodicos/index.php/ perspectiva/article/view/924.

24. Leubolt B. One or two nation projects? Discourse on inequalities and equality-related policies in South Africa and Brazil. Rev Sociol Polit [internet]. 2015 [acesso em 2018 maio 16]; 23(55);35-51. Disponível em: http://www.scielo.br/scielo.php?script=sci arttext\&pid=S0104-44782015000300035\&lang=pt.

25. Loureiro CV, Gorayeb A, Brannstrom C. Análise comparativa de políticas de implantação e resultados sociais da energia eólica no Brasil e nos Estados Unidos. Raega [internet]. 2017 ago [acesso em 2018 maio 16]; 40:231-247. Disponível em: https://revistas.ufpr.br/raega/article/view/45344

26. Martins JS. A reforma agrária no segundo mandato de Fernando Henrique Cardoso. Tempo Soc [internet]. 2003 nov [acesso em 2018 maio 16]; 15(2):141-175. Disponível em: http://www.scielo.br/scielo.php?script=sci_arttext\&pid=S0103$-20702003000200006 \& \operatorname{lng}=$ en\& $\mathrm{nrm}=$ iso.

27. Neutzling I. A crise de um modelo de desenvolvimento: notas para uma análise da conjuntura bra- 
sileira. Perspectiva Teológica [internet]. 1991 jan [acesso em 2018 maio 16]; 23(61):371-384. Disponível em: http://www.faje.edu.br/periodicos/index.php/perspectiva/article/view/1270/1668.

28. Neves LMBP. Cidadania e participação política na época da Independência do Brasil. Cad CEDES [internet]. $2002 \mathrm{dez}$ [acesso em 2018 maio 16]; 22(58):47-64. Disponível em: http://www.scielo.br/scielo.php?script=sci_arttext\&pid=S0101$-32622002000300004 \& \operatorname{lng}=$ en $\& \mathrm{nrm}=$ iso.

29. Passos JD. Os limites do carisma na instituição tradicional: Reflexões sobre as reformas do Papa Francisco em chave weberiana. Horizonte [internet]. 2015 jan [acesso 2018 maio 16]; 12(36):13841407. Disponível em: http://periodicos.pucminas. br/index.php/horizonte/article/view/7385.

30. Rodrigues AT. Democracia e mobilização social: participação autônoma e instituições políticas na transição brasileira. Rev Sociol Polit [internet]. 1999 jun [acesso em 2018 maio 16]; (12):99-119. Disponível em: http://www.scielo.br/scielo.php?script=sci_arttext\&pid=S0104$-44781999000100006 \& \operatorname{lng}=$ en\&nrm=iso.

31. Rodrigues FCM. Considerações acerca do campo jurídico e da cultura política na passagem à modernidade no brasil. Passagens Rev Intern Hist Política Cult Jurídica [internet]. 2010 [acesso em 2018 maio 16]; 2(3):39-53. Disponível em: http:// www.redalyc.org/articulo.oa?id=337327172004.

32. Rojas G. Crise capitalista mundial: a crise de hegemonia norte-americana é uma crise de dominação? Espacio Abierto [internet]. 2015 [acesso em 2018 maio 16]; 24(2):223-234. Disponível em: http://produccioncientificaluz.org/index.php/espacio/article/view/20298

33. Santos ALN, Correia MFR, Oliveira PV. A Bahia e os seus fluxos e refluxos rumo à mítica mama África: um possível campo de exercício da cooperação Sul-Sul? Cad CRH [internet]. 2016 abr [acesso em 2018 maio 16]; 29(76):87-100. Disponível em: http://www.scielo.br/scielo.php?script=sci arttext\&pid=S0103-49792016000100087\&lng=e $\mathrm{n} \& \mathrm{nrm}=\mathrm{iso}$.

34. Silva YB, Santana PV. Análise da conjuntura social em Coari a partir das responsabilidades socioambientais do município frente a acordos internacionais - o caso da Petrobrás e a agenda 21. Rev Geonorte [internet]. 2017 [acesso em 2018 maio 16]; 8(28):51-64. Disponível em: http://www.periodicos. ufam.edu.br/revista-geonorte/article/view/3508.

35. Bazzo LMF. Privação da oferta de serviços fonoaudiológicos no Sistema Único de Saúde (SUS) e a reforma do Estado: a mediação do debate. R Ciméd Biol [internet]. 2007 [acesso em 2018 maio 16]; 6(2):190-196. Disponível em: https://portalseer.ufba.br/index.php/cmbio/article/view/4211.

36. Cotta RMM, Muniz JN, Mendes FF, et al. A Crise do Sistema Único de Saúde e a Fuga para o Mercado. Ciênc Saúde Colet [internet]. 1998 jun [acesso em 2018 maio 16]; 3(1):94-105. Disponível em: http://www.scielo.br/scielo.php?script=sci arttext\&pid=S1413-81231998000100094\&lng=en \&nrm=iso.

37. Henriques AB, Porto MFS. A insustentável leveza do alumínio: impactos socioambientais da inserção do Brasil no mercado mundial de alumínio primário. Ciênc Saúde Colet [internet]. 2013 nov [acesso em 2018 maio 16]; 18(11):3223-3234. Disponível em: http://www.scielo.br/scielo.php?script=sci arttext\&pid=S1413-81232013001100013\&lng=en \&nrm=iso.

38. Luz MT. Duas questões permanentes em um século de políticas de saúde no Brasil republicano. Ciênc Saúde Colet [internet]. 2000 [acesso em 2018 maio 16]; 5(2):293-312. Disponível em: www.scielo.br/pdf/csc/v5n2/7097.pdf.

39. Matos EVM, Ferreira AMR, Palmeira IP, et al. Conjuntura epidemiológica da hanseníase em menores de quinze anos, no período de 2003 a 2013, Belém - PA. Hansen Int [internet]. 2015 [acesso em 
2018 maio 16]; 40(2):17-23. Disponível em: http:// www.ilsl.br/revista/download.php?id=imageBank/ v40n2a03.pdf.

40. Silva ET, Oliveira RT, Leles CR. O edentulismo no Brasil: epidemiologia, rede assistencial e produção de próteses pelo sistema único de saúde. Tempus Actas Saúde Colet [internet]. 2015 set [acesso em 2018 maio 16]; 9(3):121-134. Disponível em: http:// www.tempusactas.unb.br/index.php/tempus/article/view/1790.

41. Souza TS, Saldanha JHS, Mello IM. As relações de trabalho dos fisioterapeutas na cidade de Salvador, Bahia. Saúde Soc [internet]. 2014 dez [acesso em 2018 maio 16]; 23(4):1301-1315. Disponível em: http://www.scielo.br/scielo.php?script=sci arttext\&pid=S0104-12902014000401301\&lng=en $\& n r m=$ iso.

42. Teixeira CF, Paim JS. Políticas de formação de recursos humanos em saúde: conjuntura atual e perspectivas. Divulg saúde debate. 1996 jul; (12):19-23.

43. Junqueira AH, Peetz MS. Análise conjuntural do comércio exterior da floricultura brasileira. Rev Bras Horticultura Ornamental [internet]. 2010 [acesso em 2018 maio 16]; 16(1):79-81 Disponível em: http://www.hortica.com.br/artigos/2010_1_ Sem_Com_Exterior_Floricultura_Brasileira.pdf.

44. Volsi B, Telles TS, Reydon BP. Evolução dos preços das terras agrícolas no Paraná entre 1998 e 2015. Rev Ciências Agrárias [internet]. 2017 set [acesso em 2018 maio 16]; 40(3):670-682. Disponível em: http://www.scielo.mec.pt/scielo.php?script=sci arttext $\&$ pid $=$ S0871-018X2017000300019\&lng $=p t$ $\& n r m=$ iso.

45. Fonseca PCD, Cunha AM, Bichara JS. O Brasil na Era Lula: retorno ao desenvolvimentismo? Nova Econ [internet]. 2013 ago [acesso em 2018 maio 16]; 23(2):403-428. Disponível em: http://www.scielo.br/scielo.php?script=sci_arttext $\&$ pid $=$ S0103$-63512013000200006 \& \operatorname{lng}=\mathrm{en} \& \mathrm{nrm}=$ iso.
46. Oliveira NM, Piffer M. Conjuntura do desenvolvimento regional dos municípios do estado do Tocantins. Desenvol Regional debate [internet]. 2016 nov [acesso em 2018 maio 16]; 6(3):32-61. Disponível em: http://www.periodicos.unc.br/index.php/ $\mathrm{drd} /$ article/view/1023

47. Santos LP, Lima JF. Desenvolvimento econômico local em Assis Chateaubriand-PR. Desenvolv Regional debate [internet]. 2015 [acesso em 2018 maio 16]; 5(1):180-200. Disponível em: http://www.periodicos.unc.br/index.php/drd/article/view/794.

48. Torres LH. A porta lacrada para sempre ou quem matou o padre Bernardo Viegas? Biblos [internet]. 2008 [acesso em 2018 maio 16]; 22(1):119-129. Disponível em: https://periodicos.furg.br/biblos/article/view/860.

49. Zirene JDU, Zapara A. Análisis de la coyuntura económica en las empresas del municipio de Sabaneta - Antioquia. Rev Ciências Estratégicas [internet]. 2013 jul-dez [acesso em 2018 maio 16]; 22(30):301-315. Disponível em: https://revistas. upb.edu.co/index.php/cienciasestrategicas/article/view/2660.

50. Corrêa AA. Estudos pós-graduados e pesquisa em literatura: condições e necessidades. Rev Bras Pós-Graduação [internet]. 2012 [acesso em 2018 maio 16]; 9(18):705-723. Disponível em: http://ojs.rbpg. capes.gov.br/index.php/rbpg/article/view/362.

51. Magno LD, Paim JS. Dos clamores das ruas aos rumores no Congresso: uma análise da conjuntura recente da saúde no Brasil. RECIIS [internet]. 2015 dez [acesso em 2018 maio 16]; 9(4)1-14. Disponível em: https://www.reciis.icict.fiocruz.br/ index.php/reciis/article/view/1043.

52. Collins R. Quatro tradições sociológicas. Petrópolis: Vozes; 2009.

53. Souza HJ. Como se faz análise de conjuntura. 34 ed. Petrópolis: Vozes; 2014. 
54. Almeida Filho N. Integração metodológica na pesquisa em saúde: nota crítica sobre a dicotomia quantitativo-qualitativo. In: Goldenberg P, Marsiglia RMG, Gomes MHA. O clássico e o novo: tendências, objetos e abordagens em ciências sociais e saúde. Rio de Janeiro: Fiocruz; 2003. p. 143-156.

55. Paim JS. Reforma Sanitária Brasileira: contribuição para a compreensão e crítica. Salvador: Edufba; 2008.

56. Sestelo JAF. Dominância financeira na assistência à saúde: a ação política do capital sem limites no século XXI. Ciênc Saúde Colet [internet]. 2018 jun [acesso em 2018 jul 13]; 23(6):2027-2034. Disponível em: http://www.scielo.br/scielo.php?script=sci_ arttext\&pid=S1413-81232018000602027\&lng=pt.
57. Schraiber LB. Engajamento Ético-Político e Construção Teórica na Produção Científica do Conhecimento em Saúde Coletiva. In: Baptista TWF, Azevedo CS, Machado CV. Políticas, planejamento e gestão em saúde: abordagens e métodos de pesquisa. Rio de Janeiro: Fiocruz; 2015. p. 33-58.

Recebido em 15/07/2018

Aprovado em 18/09/2018

Conflito de interesses: inexistente

Suporte financeiro: Coordenação de Aperfeiçoamento de Pessoal de Nível Superior - Brasil (Capes) - Código de Financiamento 001, por meio de concessão de bolsa para Virgens JHA, durante o período de realização do estudo. O OAPS é apoiado pelo CNPq e pelo Ministério da Saúde (Chamada MCTI /CNPq/CT-Saúde/MS/SCTIE/Decit noㅜ 41/2013) 